\title{
Looking Back and Looking Forward: CNS Spectrums in the New Year
}

\author{
By Eric Hollander, MD
}

As we start the new year of 2007, it is worth taking some time to reflect on some of the accomplishments of our journal, and to give thanks to the entire CNS Spectrums team for making this a journal we can be proud of and a pleasure with which to be associated.

When this journal was first launched over a decade ago, the idea was to create a journal focused on neuropsychiatry and elucidating brainbased systems and mechanisms that would have appeal to a broad-based audience of psychiatrists and neurologists involved in clinical practice and/ or research. The idea was that brain systems could be tightly linked to core and associated symptoms domains that cut across traditional psychiatric and neurological boundaries, and present as a spectrum or cluster of related central nervous system diagnoses and symptoms. The goal was to synthesize cutting-edge areas of clinical neuroscience and to provide novel ways to think about brain-based disorders. Since then, the journal has clearly grown in terms of readership, stature, international reach, and impact factor. Yet, the content has remained highly readable and accessible.

In this first issue of 2007, Lawrence F. Blob, $M D$, and colleagues examine the effects of selegiline transdermal system on cardiovascular vital signs following tyramine. At the $6 \mathrm{mg} / 24$ hour dose, there was no evidence of a tyramine pressor effect on systolic blood pressure. This is of interest, since most young psychiatrists have no real experience with monoamine oxidase inhibitors (MAOIs), and are reluctant to prescribe them. This is especially unfortunate, since MAOls are an important tool in our psychopharmacologic armamentarium, especially for patients with social anxiety features, rejection sensitivity, and lack of response to other treatments. Thus, increasing the comfort level with MAOls should allow more patients to receive them who could also potentially benefit from such treatments.
Craig J. Gardner, DO, and Kiwon Lee, MD, describe how hypertensive encephalopathy is one of the manifestations of a hypertensive crisis associated with an abrupt rise in blood pressure. Clinical and radiographic findings associated with this diagnosis are described, and animal models discussed. Clinical management guidelines are provided, which are helpful in treatment-selection decisions.

Behavioral symptoms of dementia present a major challenge in patient management, but there is no Food and Drug Administration-indicated medication for the management of these symptoms. The FDA has issued warnings regarding the cardiac and metabolic side effects, cerebrovascular events, and, most recently, mortality risk of atypical antipsychotic agents in such patients. Subramoniam Madhusoodanan, MD, and Olivera Bogunovic, MD reviewed medical records of 58 elderly dementia patients who were taking risperidone and were abruptly switched to olanzapine following an initial warning. Even though it is generally not recommended in elderly patients, abrupt switching did not have any negative consequences in this group of patients. While clinicians are left to grapple with these most difficult patients, clearly further work needs to be done with regards to fully understanding the risks and benefits of managing this troubling symptom domain.

Next, Michael W. Otto, PhD, and colleagues describe a particular success for translational research agendas, characterization of the neuronal circuits underlying fear extinction, and basic research in animal extinction paradigms, which has led to intervention studies examining the use of D-cycloserine to enhance therapeutic learning from exposure-based cognitive-behavioral therapy. This strategy holds real potential in facilitating learning and memory acquisition in conjunction with psychosocial approaches, and could be applied to a broad range of conditions, from

Dr. Hollander is the editor of this journal, Esther and Joseph Klingenstein Professor and Chairman of Psychiatry at the Mount Sinai School of Medicine, and director of the Seaver and New York Autism Center of Excellence in New York City. 
anxiety disorders to autism, to improve real-world functioning regardless of diagnostic category.

A. Joyce Young, MD, and colleagues review coenzyme $\mathrm{Q} 10$ as a powerful antioxidant that buffers the potential adverse consequences of free radicals produced during oxidative phosphorylation in the inner mitochondrial membrane. Randomized controlled trials of antioxidant approaches seem warranted to confirm their safety and efficacy as clinically effective neuroprotectants. Complementary and alternative approaches to enhancing neuroplasticity and enhancing realworld functioning are clearly welcome.
In closing, I would like to thank our readers, who have diligently read the journal and provided us with much feedback as well as a growing number of letters to the editor. I would like to thank all of the authors and guest editors for their outstanding contributions in 2006. Special mention must be made of the peer reviewers, whose tireless efforts on behalf of scientific objectivity are acknowledged below. Finally, I would like to thank Darren Brodeur, the publisher of this journal, and his outstanding staff, with whom it continues to be a joy to work with together. CNS

\section{We would like to thank the following peer reviewers who contributed to CNS Spectrums in 2006:}

Lenard Adler, MD

Tracie 0. Afifi, MSc

Melissa Alderfer, $\mathrm{PhD}$

And rea Allen, $\mathrm{PhD}$

Alan Apter, MD

Christopher Baethge, MD

Richard Balon, MD

Rick Barnett, PsyD

Chiara Baxt, PhD

Donald W. Black, MD

Carlos Blanco, MD

Michael Bloch, MD

Charles Bowden, MD

Jennifer Boyd, MD

Peter F. Buckley, MD

Oscar Bukstein, MD

Al Camacho, MD

Javier Garcia Campayo, MD

Bernard S. Chang, MD

Kiki Chang, MD

Daniel D. Christensen, MD

Anita Clayton, MD

Eli Coleman, PhD

Andrew J. Cutler, MD

Pinhas N. Dannon, MD

Cristina Davila, MD

Colin Depp, MD

Leonard Doerfler, $\mathrm{PhD}$

Melissa Dominice Dao, MD

Stephen Durrenberger, MD

Jane Eisen, MD

Ronald M. Epstein, MD

Javier I. Escobar, MD

Lisa T. Eyler, PhD

Timothy W. Fong, MD

Leonardo F. Fontenelle, MD

Benicio N. Frey, MD, MSc

Mark Frye, MD

Richard J. Genik II, PhD

S. Nassir Ghaemi, MD, MPH

Andro Giorgadze, MD

David L. Ginsberg, MD
Don Goff, MD

Jeffrey I. Gold, PhD

Paul J. Goodnick, MD

Phillip Green, MD, MPA

Michael F. Grunebaum, MD

Sabine Miriam Grusser, PhD

Sanjay Gupta, MD

Peter Henningsen, MD

Donald Hilty, MD

Leslie Horton, MD, PhD

Lisa S. Inouye, MD, MPH

John E. Jannes, PhD

Shashank Joshi, MD

Jessica H. Kalmar, PhD

Nabil S. Kamel, MD

Deanna Kelly, PharmD

Kurt Kroenke, MD

K. Steven LaForge, PhD

Steve Lamberti, MD

Nathaniel Laor, MD, PhD

David M. Ledgerwood, PhD

Kelvin 0. Lim, MD

John-Pierre Lindenmayer, MD

Paul Mackin, MD

Anil K. Malhotra, MD

Sloan Manning, MD

Donatella Marazziti, MD

Laura Marsh, MD

Prakash Masand, MD

William M. McDonald, MD

James J. McGough, MD

Arnold W. Mech, MD

Matthew Menza, MD

Jeffrey L. Metzner, MD

Alexander L. Miller, MD

Francisco A. Moreno, MD

David Mrazek, MD, FRCPsych

Philip R. Muskin, MD

Jadwiga Najib, MD

Benjamin H. Natelson, MD

Charles O'Brien, MD, PhD

John M. Oldham, MD
Joseph O'Neill, PhD

Jill L. Ostrem, MD

Maryland Pao, MD

David L. Pauls, PhD

Timothy Petersen, MD

Katharine Phillips, MD

Teresa Pigott, MD

Steven R. Pliszka, MD

Stephen G. Reich, MD

Paula Riggs, MD

Lavinia Rossi, MD

Barbara Olasov Rothbaum, PhD, ABPP

Peter Roy-Byrne, MD

M.D. Rudd, PhD, ABPP

Ayal Schaffer, MD, FRCPC

Herbert Schreier, MD

S. Charles Schulz, MD

Daniel Schupbach, MD

David Scott, BA

Kapil D. Sethi, MD

Nathan Andrew Shapira, MD, PhD

Vivek Singh, MD

Jonathan A. Slater, MD

Gwenn S. Smith, PhD

Brent Solvason, MD

Helle Spindler, MSc, PhD Fellow

Geoffrey M. Stephenson, PhD

Eric A. Storch, PhD

Daniel Tarsy, MD

Roland von Kanel, MD

David P. Walling, PhD

Arthur S. Walters, MD

P.O. Wang, MD

Braxton B. Wannamaker, MD

Danuta Wasserman, MD, PhD

Patrice L. (Tamar) Weiss, PhD

Simon Wessely, MA, BM, BCh, MSc, MD,

FRCP, FRCPsych, FMedSci

John Winkelman, MD, PhD

Donna Wirshing, MD

Ellen F.T. Yee, MD, MPH 